\title{
Long-Term Behavior of Simulated Partial Lead Service Line Replacements
}

\author{
Justin St. Clair, Clement Cartier, ${ }^{2}$ Simoni Triantafyllidou, Brandi Clark, ${ }^{1, *}$ and Marc Edwards ${ }^{1, * \star}$ \\ ${ }^{1}$ Virginia Tech, Civil and Environmental Engineering, Blacksburg, Virginia. \\ ${ }^{2}$ Claro, Inc., Montreal, Canada.
}

Received: August 29, $2015 \quad$ Accepted in revised form: October 29, 2015

\begin{abstract}
In this 48-month pilot study, long-term impacts of copper:lead galvanic connections on lead release to water were assessed without confounding differences in pipe exposure prehistory or disturbances arising from cutting lead pipe. Lead release was tracked from three lead service line configurations, including (1) $100 \%$ lead, (2) traditional partial replacement with 50\% copper upstream of 50\% lead, and (3) 50\% lead upstream of 50\% copper as a function of flow rate, connection types, and sampling methodologies. Elevated lead from galvanic corrosion worsened with time, with $140 \%$ more lead release from configurations representing traditional partial replacement configurations at 14 months compared to earlier data in the first 8 months. Even when sampled consistently at moderate flow rate (8 LPM) and collecting all water passing through service lines, conditions representing traditional partial service line configurations were significantly worse $(\approx 40 \%)$ when compared to $100 \%$ lead pipe. If sampled at a high flow rate (32 LPM) and collecting $2 \mathrm{~L}$ samples from service lines, $100 \%$ of samples collected from traditional partial replacement configurations exceeded thresholds posing an acute health risk versus a $0 \%$ risk for samples from $100 \%$ lead pipe. Temporary removal of lead accumulations near $\mathrm{Pb}: \mathrm{Cu}$ junctions and lead deposits from other downstream plastic pipes reduced risk of partial replacements relative to that observed for $100 \%$ lead. When typical brass compression couplings were used to connect prepassivated lead pipes, lead release spiked up to 10 times higher, confirming prior concerns raised at bench and field scale regarding adverse impacts of crevices and service line disturbances on lead release. To quantify semirandom particulate lead release from service lines in future research, whole-house filters have many advantages compared to other approaches.
\end{abstract}

Key words: corrosion; drinking water; galvanic corrosion; lead; partial lead service line replacement

\section{Introduction}

$\mathbf{T}$ 'he Environmental Protection Agency's (EPA) Lead and Copper Rule (LCR) was implemented to minimize lead and copper exposure from drinking water by various interventions, including replacement of lead service pipes. However, there is growing concern that the action of replacing a portion of lead service line with a copper pipe, to reduce consumer lead exposure, may not always be effective and in some cases actually increases exposure (Britton and Richards, 1981; US EPA, 1991, 2011; Swertfeger et al., 2008, 2011; Muylwyk et al., 2011). Specifically, when utilities partially

\footnotetext{
*Member of AEESP

** Corresponding author: Virginia Tech, Civil and Environmental Engineering, 418 Durham Hall, Blacksburg, VA 24061. Phone: 540231-7236; Fax: 540-231-7916; E-mail: edwardsm@vt.edu

(C) Justin St. Clair et al. 2015; Published by Mary Ann Liebert, Inc. This Open Access article is distributed under the terms of the Creative Commons Attribution Noncommercial License (http:// creativecommons.org/licenses/by-nc/4.0/) which permits any noncommercial use, distribution, and reproduction in any medium, provided the original author(s) and the source are credited.
}

replace lead service lines with a copper pipe, either in response to requirements of the LCR or voluntarily, galvanic corrosion between the lead and newly installed copper and brass connectors can increase lead corrosion rates, which can either cancel or reverse anticipated benefits of having less lead pipe (Triantafyllidou and Edwards, 2010, 2011; Cartier et al., 2012a; Giammar et al. 2012; Wang et al., 2013).

A range of factors are suspected to influence the extent of galvanic corrosion between copper and lead, including flow rate, connector type, deposition corrosion, lead surface passivation, relative position of lead versus copper pipe, presence of crevices, and corrosivity of water (Triantafyllidou and Edwards, 2010; US EPA, 2011; Xie and Giammar, 2011; Cartier et al., 2012a, 2013; Hu et al., 2012; St. Clair et al., 2012; Wang et al., 2012, 2013; Clark et al., 2013; Zhou et al., 2015). Better understanding the duration of the adverse galvanic effects is extremely important, as early practical work suggested that such impacts could be sustained for years or decades (Britton and Richards, 1981). A few recent reports by EPA and others speculated that such effects would be insignificant and sustained only for days or a few weeks (Reiber and Dufresne, 2006; National Drinking Water 
Advisory Council, 2011; US EPA, 2011; Boyd et al., 2012), although an "expression of concern" is now associated with that work as detailed elsewhere (Edwards, 2012; Retraction Watch, 2015). All recent studies that rigorously examined the issue at bench or pilot scale (up to 8 months duration) concluded that problems with elevated lead from galvanic corrosion and partial replacements could be sustained over the entire duration of the experiments (Triantafyllidou and Edwards, 2011; Cartier et al., 2012a, 2013; Doré et al., 2012; Wang et al., 2012). Moreover, a recent study in Chicago by US EPA also reported longer term adverse consequences of partial lead service line replacement (PLSLR) (i.e., disturbed lead service lines) in terms of elevated lead in water risks (Del Toral et al., 2013).

Detection of elevated lead problems from galvanic corrosion has been complicated by differing results dependent on flow rate and sampling methodologies, and recommended sampling methods for compliance monitoring are still under review (US EPA, 2012). If water samples are collected at low flow, lead particulates and sediments are not mobilized, which can hinder detection of visible deposits of lead scale created at the lead:copper pipe connection due to galvanic corrosion (Deshommes et al., 2010; Triantafyllidou and Edwards, 2011; Cartier et al., 2012a). Samples collected at moderate (8 LPM) and higher flow rates (32 LPM) from partially replaced lead pipe configurations revealed sporadic detachment of lead particulates at levels posing an acute health risk (Cartier et al., 2012a). The latter observation could explain why a higher incidence of elevated blood lead in children was reported in homes with partial pipe replacements versus undisturbed lead service lines (Brown and Margolis, 2012), and higher rates of fetal death were noted to occur during periods of partial pipe replacements (Edwards, 2014), even when routine sampling of such homes at low flow rates did not detect serious problems (Giani et al., 2004; Giani, 2008). Practical sampling methods that are capable of better detecting semirandom release of lead particulates that can pose an acute health risk to consumers (McNeill and Edwards, 2004; Triantafyllidou et al., 2007) are needed.

Other factors have been speculated to play a role in service line corrosion and galvanic impacts arising from lead:copper connections. For instance, copper and lead pipe sections are cathodic to iron water mains, which imply that lead connections to unlined iron might be cathodically protected from corrosion (Clark et al., 2013), consistent with other anecdotal field evidence suggesting that iron mains cathodically protect copper service lines when they are directly connected in the distribution system (Gehring et al., 2003; Rajani and Kleiner, 2003). It is hypothetically possible that an iron main coupled to a lead service line could provide cathodic protection to the lead or, possibly, eliminate galvanic corrosion of the lead in a partial pipe replacement if unlined iron mains are present. If this protection was significant, replacement of unlined iron mains with either new lined pipes or plastic, as occurs routinely with infrastructure upgrades, might also produce increased lead contamination of water. There are no laboratory studies refuting or supporting these hypothesized effects. Prior bench scale research also suggested that partially replacing lead pipes with copper can create much more serious problems with lead contamination of water during prolonged stagnation events when compared to a situation with a $100 \%$ lead pipe (Triantafyllidou and Edwards, 2010; Arnold and Edwards, 2012; Cartier et al., 2012a).

The goal of the current work is to (1) extend data collection in the 8-month pilot study described in Cartier et al. (2012a) to a time period of $>2.5$ years, (2) better define the nature of elevated lead release after partial pipe replacements, (3) examine galvanic impacts on prepassivated lead pipes using "real" brass connectors, (4) evaluate the strengths/weaknesses of sampling protocols that could detect public health concerns arising from partial pipe replacements, (5) conduct preliminary analysis of unlined iron main impacts on corrosion of service lines, and (6) determine how prolonged stagnation periods influence lead release.

\section{Materials and Methods}

The pilot is that described by Cartier et al. (2012a) using Blacksburg tap water, but extending the previously reported results from 8 months to a total time of 48 months of operation. Blacksburg tap water is relatively noncorrosive due to $\mathrm{pH}$ adjustment and dosing of a zinc orthophosphate corrosion inhibitor. Three configurations representing a full-lead service line $(100 \% \mathrm{~Pb})$, a PLSLR with lead downstream of copper $(\mathrm{Pb}-$ $\mathrm{D} ; 50 \% \mathrm{Cu}$ and $50 \% \mathrm{~Pb}$ ), and a PLSLR with lead upstream of copper $(\mathrm{Pb}-\mathrm{U} ; 50 \% \mathrm{~Pb}$ and $50 \% \mathrm{Cu})$ were tested in triplicate. Each 50:50\% pipe section was galvanically coupled with an external wire. A $100 \%$ copper control was also tested. Four phases of research tested three different sampling methods (Table 1). During all test phases, galvanic corrosion currents were continually measured by a zero-resistance ammeter using a GAMRY Potentiostat. During months 8-13, the pilot operated at low flow and was not sampled.

Phase A: The pilot was operated and sampled like that described by Cartier et al. (2012a) during months 13-14, including low, moderate, and high flow rates. A first draw, $2 \mathrm{~L}$, sample was collected after 16-h stagnation periods for all three flow rates. After the flushing events, filtered samples were immediately collected from the $2 \mathrm{~L}$ sample to quantify soluble lead using a $0.45 \mu \mathrm{m}$ filter. Thereafter, the $2 \mathrm{~L}$ first draw and filtered sample were acidified with nitric acid to a concentration of $2 \% \mathrm{v} / \mathrm{v}$ and allowed to digest for a minimum of 5 days before analysis through an inductively coupled plasma mass spectrometer according to the Standard Method 3125B (APHA, 1998).

Phase B: From months 15-22, consistent flow rates emulating a household faucet (8-9 LPM) were tested, in contrast to the earlier work (months $0-15$ ) in which flow rates were 1.3 LPM, except during sampling events. Daily composites (five times per week) of all water flowing through the pipes from three flow events per day $(2 \mathrm{~min}$ of flow after $8 \mathrm{~h}$ of stagnation) were collected in separate bins for each replicate (48 L total per rig; Phase B-1). On Mondays, the composite included a flow event after a $54 \mathrm{~h}$ weekend stagnation period. Sample aliquots from each unacidified bin were collected after rigorously stirring the bins to mobilize any particulates; QA/QC by decanting the top fraction and acidification of the remaining $2 \mathrm{~L}$ demonstrated that this approach did not systematically underquantify particulate lead $(<10 \%$ error).

To evaluate how accumulations of lead deposits (i.e., reservoirs in the plumbing, including lead scale on pipe at the copper junction or walls of copper and downstream plastic plumbing that might have been coated with lead) were 
Table 1. Experimental Phases and Sampling Methods

\begin{tabular}{lcll}
\hline Phase & $\begin{array}{c}\text { Time period (months } \\
\text { during experiment) }\end{array}$ & \multicolumn{1}{c}{$\begin{array}{c}\text { Experimental change } \\
\text { from Cartier et al. (2012a) }\end{array}$} & \multicolumn{1}{c}{ Sampling method } \\
\hline A & $13-14$ & No change & $\begin{array}{c}\text { Same as Cartier et al. } \text { (2012a), (first 2 L sample } \\
\text { and grab samples) } \\
\text { Collection of all water passing through pipes (bins) }\end{array}$ \\
B-1 & $15-17$ & Consistent 8-9 LPM flow rate & \\
B-2 & $17-18$ & Removed 4" coupons & \\
B-3 & $19-22$ & Replaced copper piping & Collection of all water passing through pipes (bins) \\
C & $22-25$ & Installed connectors & $\begin{array}{l}\text { First 2 L sample } \\
\text { D }\end{array}$ \\
E & $26-27$ & Prolonged stagnation events & Whole-house filters \\
\hline
\end{tabular}

contributing to lead release, reservoirs of lead that could accumulate in the plumbing system were systematically removed and replaced. Specifically, after 17 months (492 days), the lead coupons with heavy galvanic corrosion products at the copper junction were removed, and the rigs were then sampled during months 17-18 (Phase B-2; days 493-524). Thereafter, for both the $\mathrm{Pb}-\mathrm{U}$ and $\mathrm{Pb}-\mathrm{D}$ triplicates, the old copper pipes were replaced with new copper during month 19 (day 560) and sampled for lead release during months 21-22 (Phase B-3; days 623-643) and the rig was sampled for lead release.

The mass of lead deposits in each of the above sections was quantified. Easily removed lead rust was cleaned from the lead coupons, and total lead mass and weight loss were calculated. Copper pipe sections were filled with deaerated $10 \%$ hydrochloric acid to dissolve most of the lead that remained on the copper pipe sections. Finally, the plastic plumbing downstream of the metal pipe sections was acid cleaned and the mass of lead was quantified.

Phase $C$ : This portion of the research explored how new low lead $(<1 \%)$ brass connectors might enhance lead leaching from passivated lead service lines through galvanic corrosion without any pipe cutting. Side experiments demonstrated very low lead leaching $(<5 \mathrm{ppb})$ from the brass used in this research. Three types of connections representing extremes encountered in practice were tested, including a brass compression fitting, copper sleeve (which has crevices similar to compression fitting, but made of copper only and thus presents no potential for lead contamination, identical to Clark et al., 2013), and the existing clear plastic tubing connection with a small dielectric spacer. A baseline for lead release was established for each of the pipe rigs during the final stage of Phase B. On the basis of the baseline results, the pipe with the highest lead release remained connected as before with plastic tubing. The pipe with the lowest baseline lead release was connected using a copper sleeve, and the pipe with the middle level of lead release was connected using a brass compression fitting (same corporation valve as Clark et al., 2013). From months 22-25, all water flowing from each rig was collected in bins from each condition and sampled as per Phase B.

Phase D: During months 26-27 the rigs underwent two 1month-long stagnation events. The prolonged stagnation events represented conditions of prolonged homeowner absences with long periods of little to no flow. After each stagnation event, a $2 \mathrm{~L}$ first draw was collected from each rig at a flow rate of 15 LPM during a 5-min flow event. The $2 \mathrm{~L}$ samples were acidified and analyzed as described previously.
Phase E: After extensive bin sampling during Phase $\mathrm{C}$, whole-house filter cartridges (polypropylene, $1 \mu \mathrm{m}$ ), used to filter water at the point of entry, were installed downstream of the various rigs to collect and quantify lead release. During months 28-34, rigs were flushed at 18-20 LPM for $5 \mathrm{~min}$, three times per day, to achieve a total daily volume of $\sim 300 \mathrm{~L}$ per rig; during this phase, flow events continued over weekend periods with no 54-hr stagnation event. Filters were allowed to collect lead for periods of 38 days. Thereafter, filter housings and cartridges were removed and acidified with nitric acid to a concentration of $5 \%$ v/v. Sample aliquots were taken after $120 \mathrm{~h}$ digestion and analyzed through ICP-MS as described previously. From months 3548 , rigs operated under the same conditions and filters were collected and analyzed every 3-4 months following the procedure outlined above. During these periods, $2 \mathrm{~L}$ first draws were also collected at the beginning of flushing events.

Phase F: Concerns related to unlined iron main connections to services lines were explored using a small $10.2 \mathrm{~cm}$ lead pipe section that was coupled to a $305 \mathrm{~cm}$ galvanized iron pipe section through varying lengths of copper pipe ranging from 2.5 to $305 \mathrm{~cm}$ copper using clear plastic tubing; a control condition consisted of the lead and galvanized iron (no copper in between) connected by the plastic tubing. The apparatus was filled with Blacksburg water, and the sacrificial galvanic currents to the lead were measured immediately using a handheld multimeter. Then, the experiment was repeated with varied lengths of copper pipe. Testing demonstrated that a zero resistance ammeter and the multimeter gave equivalent results to within $\pm 5 \%$.

Another short-term experiment briefly connected $3 \mathrm{~m}$ of galvanized iron to the first section of the pilot in the flow sequence. Each rig was filled with water, and the galvanic current sacrificing the lead was quantified.

Statistical analyses were performed using Student's $t$-test. All confidence testing reported herein was conducted at the 95\% confidence level $(p<0.05)$, unless otherwise stated.

\section{Results and Discussion}

Six experimental objectives of the work are addressed sequentially in the sections that follow.

\section{Phase A: low, moderate, high flow sampling}

Trends in lead release through 9-14 months mirrored those obtained during the 8-month pilot reported by Cartier et al. (2012a), confirming that serious water contamination problems arising from galvanic connections can certainly persist 


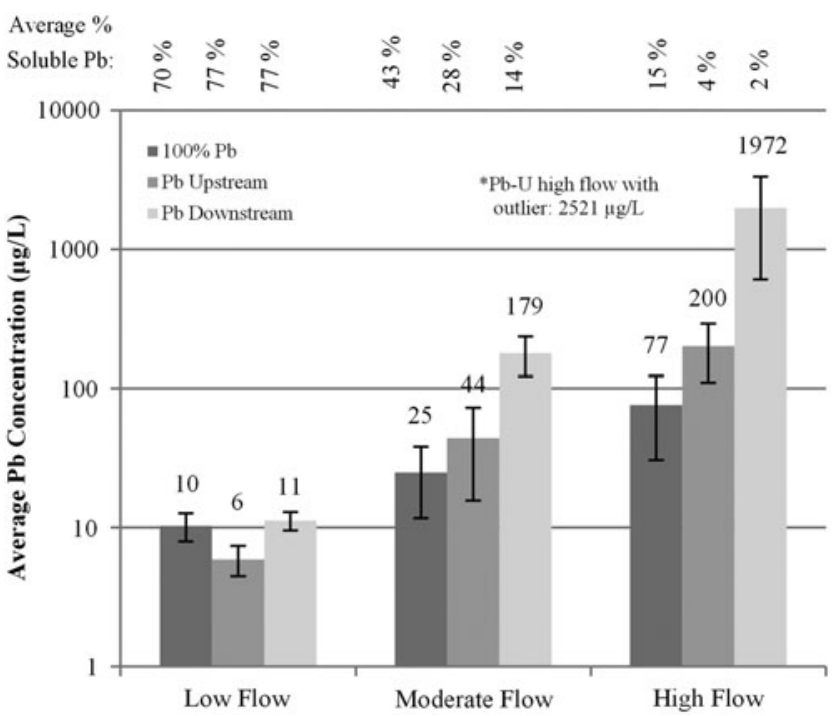

FIG. 1. Average lead concentration in water after 14 months from three sampling periods as described by Cartier et al. (2012a) with average soluble lead percentage in samples. Error bars represent $95 \%$ confidence interval. *High flow rate, $\mathrm{Pb}-\mathrm{U}$ condition excludes high outlier of $20,090 \mu \mathrm{g} /$ L. ( $N=9,3$ sampling events of triplicates).

for years, as suggested in earlier field sampling (Britton and Richards, 1981; Del Toral et al., 2013). Lead release increased for samples collected at a higher flow rate for all three conditions $(100 \% \mathrm{~Pb}, \mathrm{~Pb}-\mathrm{U}$, and $\mathrm{Pb}-\mathrm{D})$, but the worst case was the configuration created by partial replacement, with lead pipe after copper pipe in the flow sequence $(\mathrm{Pb}-\mathrm{D}$ rigs; Fig. 1). Specifically, at low flow rates over this time period, average lead concentrations were not statistically different among the tested service line configurations, but at moderate and high flow rate sampling, the condition with $\mathrm{Pb}-\mathrm{D}$ vs $100 \%$ full-lead pipe was 7 and 26 times higher, respectively $(p<0.05)$. Filtered samples were analyzed to determine the soluble fraction of lead in the first $2 \mathrm{~L}$ flush (Fig. 1). During low flow, a major fraction of lead was soluble (70-80\%) for all conditions. As flow rate increased particulate lead became the dominant fraction of lead released (e.g., at high flow, soluble lead $<5 \%$ of the total lead in both the $\mathrm{Pb}-\mathrm{U}$ and $\mathrm{Pb}-\mathrm{D}$ conditions).

Comparison of these results to the 8-month study of Cartier et al. (2012a) obtained using the same apparatus; at high flow rate, lead release decreased $68 \%(240 \mu \mathrm{g} / \mathrm{L}$ to $77 \mu \mathrm{g} / \mathrm{L})$ for the $100 \% \mathrm{~Pb}$ and $52 \%$ for $\mathrm{Pb}-\mathrm{U}(416 \mu \mathrm{g} / \mathrm{L}$ to $200 \mu \mathrm{g} / \mathrm{L})$ configuration after the initial study period. Conversely, for $\mathrm{Pb}-\mathrm{D}$, lead release increased $135 \%$ ( $839 \mu \mathrm{g} / \mathrm{L}$ to $1972 \mu \mathrm{g} / \mathrm{L})$ during months 13-14 compared to the first 8 months of the pilot. These are unambiguous data demonstrating that the elevated lead originating from configurations of partial replacements, in which a copper pipe is placed upstream of the lead pipe, does not necessarily ameliorate with time but can actually worsen.

At low flow, only one sample (11\%) from the service line for the condition with $100 \% \mathrm{~Pb}$ and $\mathrm{Pb}-\mathrm{D}$ exceeded the LCR action level of $15 \mu \mathrm{g} / \mathrm{L}$; while at high flow, $100 \%$ of samples exceeded the EPA action level (Fig. 2). Moreover, lead concentrations in $100 \%$ of samples collected from the $\mathrm{Pb}-\mathrm{D}$ service line at high flow even exceeded acute health risk standards of $>700 \mu \mathrm{g} / \mathrm{L}$ as per the analysis of Cartier et al. (2012a), whereas only $11 \%$ of Pb-U and $0 \%$ of full-lead pipe samples exceeded this threshold (Triantafyllidou, 2014; Fig. 2). This result provides a basis for heeding prior warnings to avoid placing copper in front of lead in the flow path sequence (Britton and Richards, 1981; Breach et al., 1991; Copper Development Association, 1999; Triantafyllidou and Edwards, 2010, 2011; Clark et al., 2011; Cartier et al., 2012a) and health warnings especially for young children and developing fetus (Edwards, 2014). Moreover, the results indicate that collecting samples at low flow rates, or forcing consumers to collect samples at low flows by providing bottles with very small openings as is now commonplace in many cities, can dramatically underestimate water lead levels that can be present during normal use.

\section{Phase B: consistent moderate flow sampling}

It was hypothesized that detriments of partial replacements and galvanic corrosion might disappear if flow rates were maintained at very consistent levels and all water from the rig was collected. During the first 8 weeks of sampling with flow at 8 LPM and collecting all the water (Phase B-1), the
FIG. 2. Percentage of first $2 \mathrm{~L}$ service line samples exceeding $15 \mu \mathrm{g} / \mathrm{L}$ (LCR action level) and $700 \mu \mathrm{g} / \mathrm{L}$ (acute health risk level) during Phase $\mathrm{A}-$ low, moderate, and high flow sampling $(N=9,3$ sampling events of triplicates).

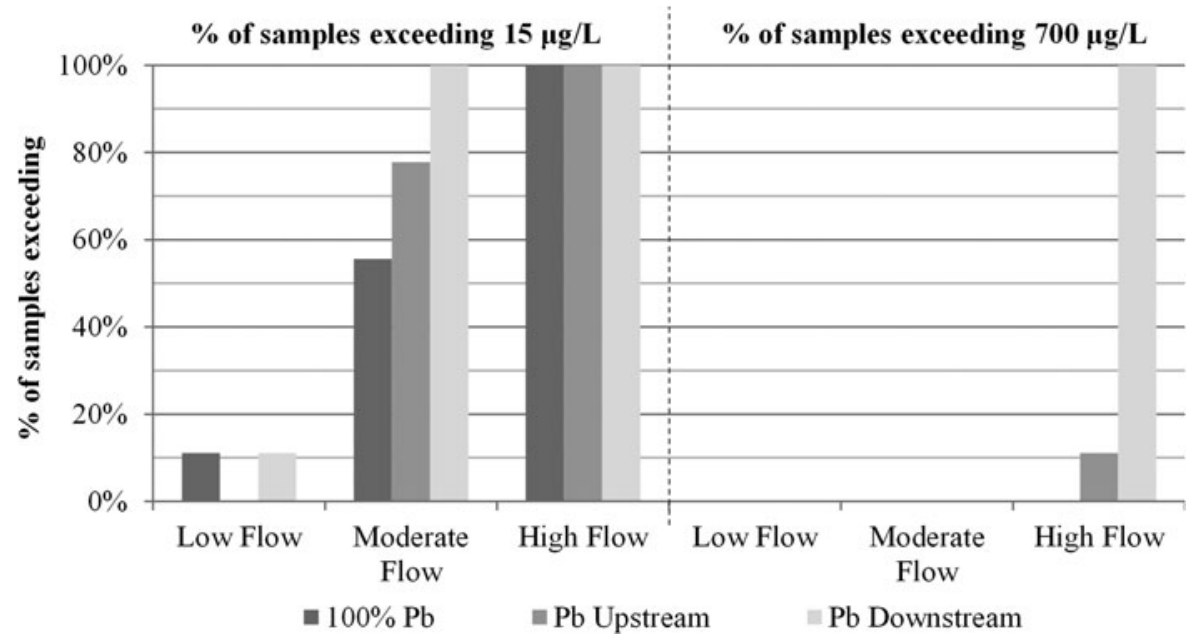




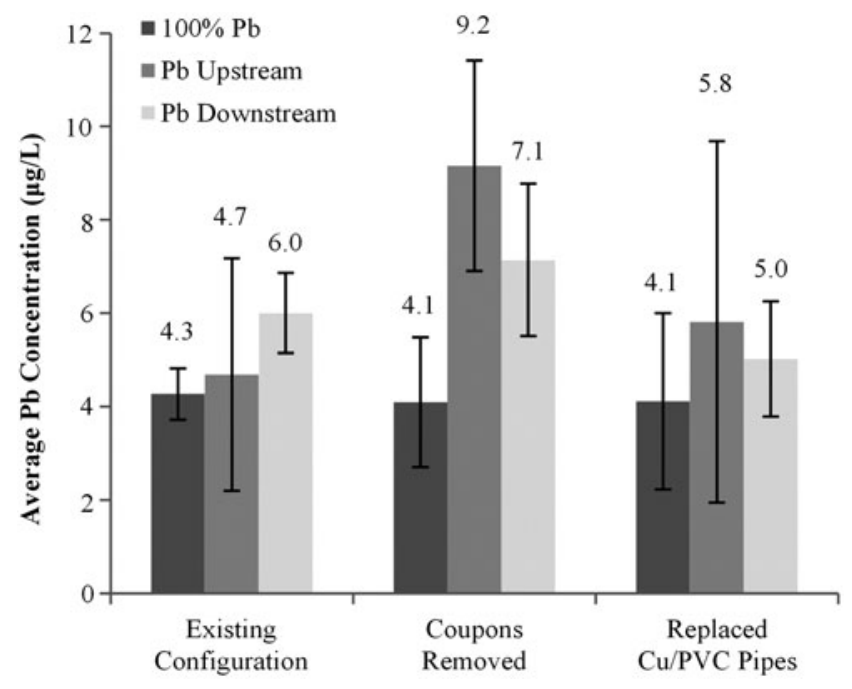

FIG. 3. Average $\mathrm{Pb}$ release during various stages of Phase $\mathrm{B}$. Error bars represent 95\% confidence interval (data from replicated pooled for each individual condition). (Phase B-1, $N=69$; Phase B-2, $N=27$; Phase B-3, $N=45$ ).

concentration of lead was not statistically different for conditions representing $100 \% \mathrm{~Pb}$ pipe or if a lead service line was followed by copper (Pb-U) (Fig. 3). However, the $\mathrm{Pb}-\mathrm{D}$ was $40 \%$ worse than the $100 \% \mathrm{~Pb}$ condition $(100 \% \mathrm{~Pb}: 4.3 \mu \mathrm{g} / \mathrm{L}$, $\mathrm{Pb}-\mathrm{D}: 6.0 \mu \mathrm{g} / \mathrm{L}, p<0.05)$. In other words, even if the flow rate was maintained at stable and normal levels, the average lead release in $48 \mathrm{~L}$ sampled from a partial pipe replacement configuration is statistically worse than a full-lead service line with twice the lead pipe surface area.

\section{Lead reservoirs}

Elevated galvanic currents are expected to contribute to a reservoir of lead in the pipe rigs and especially at the junction between lead and copper (Triantafyllidou and Edwards, 2011; Cartier et al., 2012a). The mounds of lead corrosion products at the lead:copper junction became more prominent as the study progressed (Fig. 4, 492 days compared to 281 days, fig. 7-Cartier et al., 2012a). However, lead might also accumulate on other surfaces in the rigs (copper, plastic pipe downstream of the metal pipe), similar to prior observations made for lead accumulations in plumbing of homes with galvanized iron installed downstream of lead service lines (HDR Engineering, Inc., 2009). The potential contribution from each reservoir was examined sequentially.
To assess the lead released from the previously formed mounded lead rust (Phase B-2), the $10 \mathrm{~cm}$ lead coupons immediately adjacent to the copper pipe were completely removed from the rigs without replacement. Thereafter, the $\mathrm{Pb}-\mathrm{D}$ condition remained $73 \%$ higher than the $100 \% \mathrm{~Pb}$ condition (Fig. $3 ; p>0.05$ ), and the $\mathrm{Pb}-\mathrm{U}$ condition was $125 \%$ higher than the $100 \% \mathrm{~Pb}$ condition $(p<0.05)$. After the existing copper and plastic piping downstream of the lead pipe was also replaced (Phase B-3), lead release was not statistically different among the three conditions (Fig. 3). Hence, removal of all three possible reservoirs of particulate lead (lead junction, copper pipe, plastic pipe) finally produced a situation in which conditions with $50 \%$ lead pipe were at least temporarily not worse than the $100 \%$ lead pipe. This restored the rig to relative performances noted in the earliest phases (months 1-3) of the study (Cartier et al., 2012a), before reservoirs of lead particulates had accumulated throughout the plumbing system. In addition, replacing the old passivated copper pipe with a new copper pipe did not worsen the galvanic corrosion currents between lead and the copper pipe (comparing coupons removed to $\mathrm{Cu}$ replaced in Fig. 5).

Quantification of the mass of lead rust accumulation within the different parts of the plumbing system was revelatory and consistent with previously defined trends for lead release. Visually, a larger accumulation of lead rust was present on the lead surface nearest to the galvanic junction in the PLSLR conditions, whereas there was little or no accumulation on the lead pipe surface of the $100 \% \mathrm{~Pb}$ rigs (Fig. 4). When surface deposits (i.e., rusts) were later gently removed from all the removed pipe surfaces and weighed (Fig. 6), the mass of lead recovered in the conditions with galvanic corrosion was markedly greater than the $100 \% \mathrm{~Pb}$ replicates $(\mathrm{Pb}-\mathrm{U}: 2.4$ times higher, $\mathrm{Pb}-\mathrm{D}$ : 3.5 times higher). This verifies the concerns originally expressed by Triantafyllidou and Edwards (2011) regarding galvanically induced accumulations of lead deposits and provides mechanistic support for the data indicating that pipes with galvanic $\mathrm{Pb}: \mathrm{Cu}$ sections had a greater mass of lead mobilized at higher flow.

\section{Galvanic corrosion current}

In theory, as long as galvanic corrosion currents persist between lead and copper, problems with sporadic and elevated lead can also persist, and expected benefits of having a $50 \%$ lower lead surface area may never be realized. Galvanic currents remained elevated throughout the entire 48 months of the study, but eventually decreased somewhat relative to levels observed during the first year (Fig. 5). Removing the lead coupons or replacing the old copper with a new copper pipe did not result in an increase of galvanic current. From

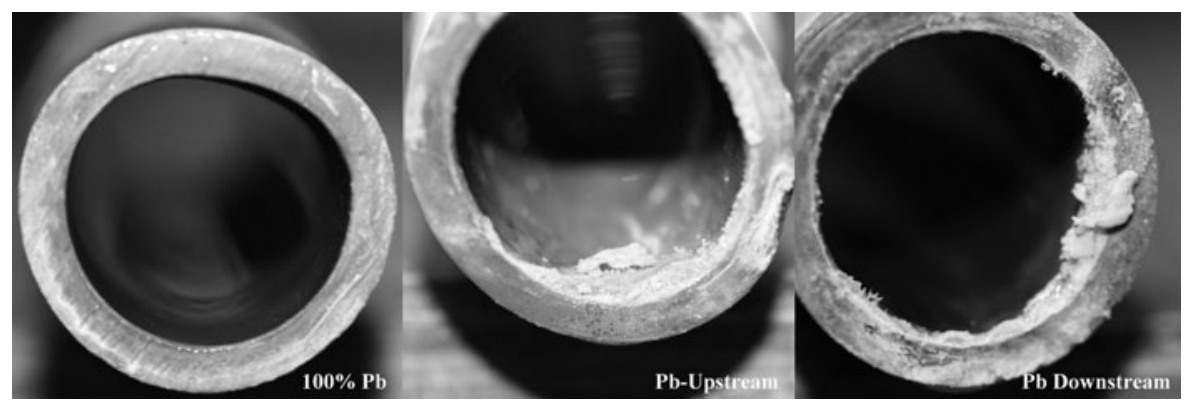

FIG. 4. Visual comparison of lead rust buildup on pipe coupons with and without galvanic corrosion after 17 months (492 days) of experiment. Large mounds of rust from partials were localized at the end closest to the $\mathrm{Cu}: \mathrm{Pb}$ junction. 


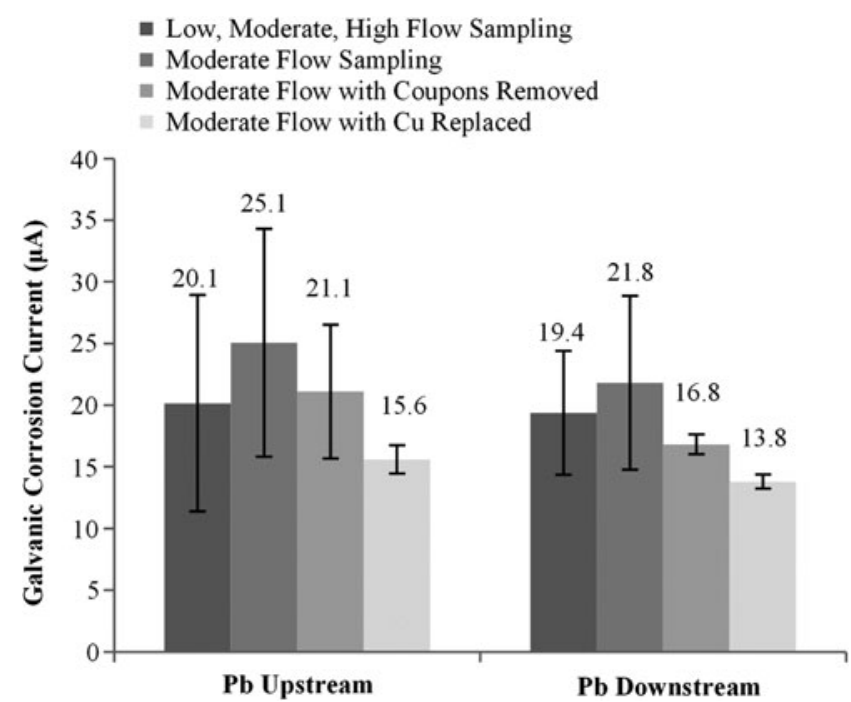

FIG. 5. Galvanic corrosion currents during Phase A (low, moderate, and high flow rate sampling per Cartier et al. 2012a) and Phase B (moderate flow rate sampling). Pb-U and $\mathrm{Pb}-\mathrm{D}$ averages and $95 \%$ confidence intervals calculated from average current of individual triplicates from each condition.

initial experimental conditions to the final stage of Phase B (months 20-22), galvanic currents decreased 35-50\% over the nearly 2 -year period. $\mathrm{Pb}-\mathrm{U}$ galvanic corrosion current decreased from $25 \mu \mathrm{A}$ to $20 \mu \mathrm{A}$ after the first year and decreased further to $16 \mu \mathrm{A}$ after 22 months. The $\mathrm{Pb}-\mathrm{D}$ galvanic current decreased from $29 \mu \mathrm{A}$ to $19 \mu \mathrm{A}$ in the first year and then to $14 \mu \mathrm{A}$ after 22 months.

The expected weight loss of the short solid $\mathrm{Pb}$ pipe sections should be at least that calculated by Faraday's Law and the integrated sacrificial current (Supplementary Fig. S1). In this work, Faraday's Law overestimated actual weight loss by a factor of 4-5; however, it is clear that there was a greater weight loss with higher galvanic current (Fig. 6) compared to the condition with $100 \%$ lead and no galvanic current. In addition, galvanic current for $\mathrm{Pb}-\mathrm{U}$ was generally higher than $\mathrm{Pb}-\mathrm{D}$ $(p>0.05)$, but average weight loss was greatest for $\mathrm{Pb}-\mathrm{D}$ (Fig. $6)$. The discrepancy between weight loss predicted by Fara- day's law versus that observed might be due to deposition (plating) of copper ions onto lead pipe surfaces causing a weight gain (Hu et al., 2012; Clark et al., 2015), which is hinted at by an increase in the ratio of copper to lead in the scale for cases with partial replacements (Supplementary Fig. S2). Alternatively, the discrepancy could also be explained by difficulties in removing all the lead deposits/scales with the gentle abrasion used herein or possible presence of reactions other than lead oxidation contributing to galvanic corrosion currents.

\section{Phase C: influence of connectors}

Many different types of brass devices can be used to connect lead to a copper pipe, and it has recently been demonstrated that certain brass devices with crevices have high propensity to cause much worse elevated lead in water than direct connections between lead and copper pipe (Clark et al., 2013). Others have speculated that connection of well passivated lead to copper or brass will not create significant problems with elevated lead in water (Reiber and Dufresne, 2006). However, recent work in Chicago demonstrated a significant problem with elevated lead if lead pipes were disturbed and a brass connector was used (Del Toral et al., 2013). These issues were tested for the lead pipe, which had been prepassivated for 2 years in this research, with no freshly cut lead surfaces present.

Before the brass or copper connections were made, there was no statistical difference in the average concentration of total lead in water between each replicate during the initial 3week baseline experiment without brass connectors (last 3 weeks of Phase $\mathrm{B} ; 100 \% \mathrm{~Pb}=4.1 \mu \mathrm{g} / \mathrm{L}, \mathrm{Pb}-\mathrm{U}=5.8 \mu \mathrm{g} / \mathrm{L}, \mathrm{Pb}-$ $\mathrm{D}=5.0 \mu \mathrm{g} / \mathrm{L})$. After installation of a commercially available brass device with crevices or a copper sleeve (to simulate brass without lead), lead release for the control conditions (existing plastic connector) decreased, but the lead concentrations for the copper sleeve increased significantly by 3.7 times (Fig. 7, $p<0.05$ ). Lead release from the $100 \% \mathrm{~Pb}$ rig coupled with a brass compression connector increased 10fold $(p<0.05)$, and the $\mathrm{Pb}-\mathrm{U}$ and $\mathrm{Pb}-\mathrm{D}$ rigs with brass connectors increased significantly by 6.2 times and 3 times $(p<0.05)$, respectively.

Total galvanic corrosion current sacrificing the lead pipe increased by 215 and $357 \%$ for the conditions connected with the copper sleeve or brass compression fitting, respectively
FIG. 6. Average weight loss from $10 \mathrm{~cm}$ lead sections (coupons), and average mass of lead recovered from individual reservoirs for each condition.

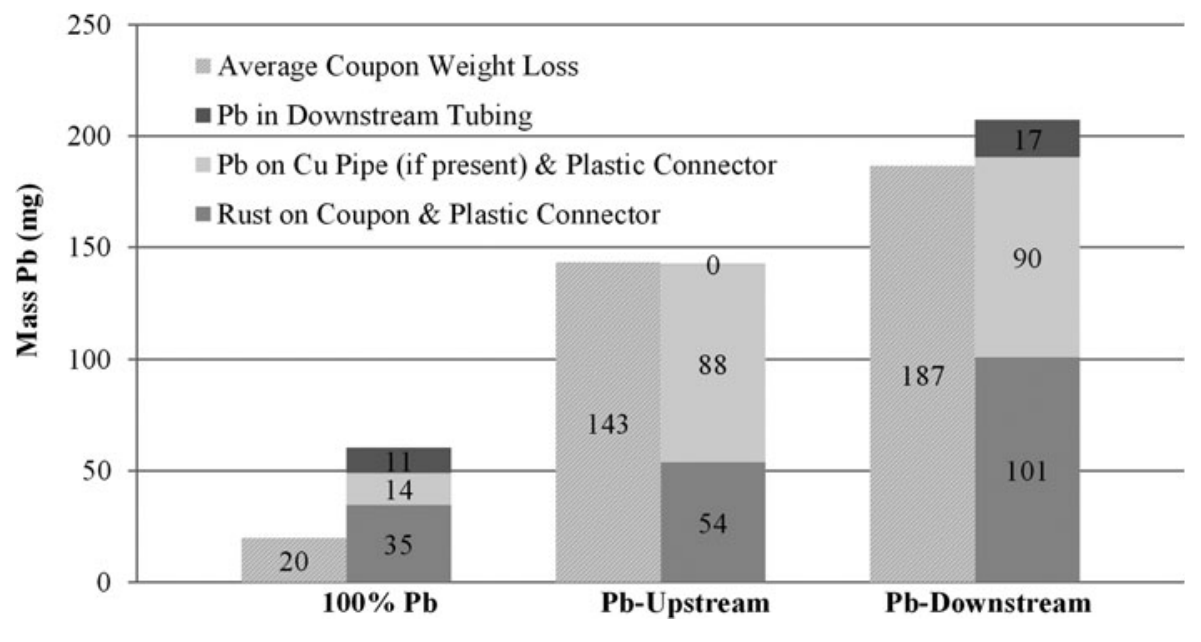




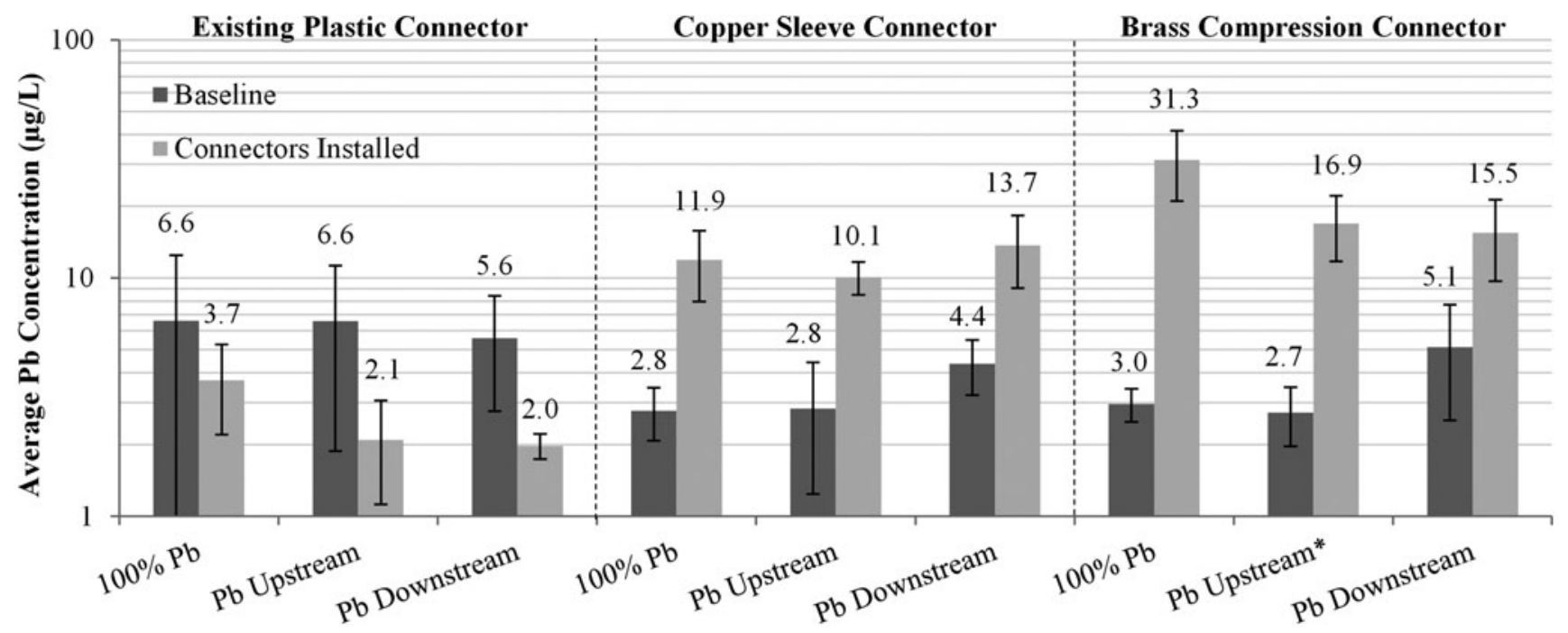

FIG. 7. Average $\mathrm{Pb}$ concentration in water during baseline period and after installing connectors. Error bars represent 95\% confidence interval. (Baseline $N=15$ per triplicate, Connectors installed $N=55$ per triplicate) *High outlier excluded from $\mathrm{Pb}-\mathrm{U} 3$ baseline.

(Fig. 8; note that galvanic current is zero for $100 \% \mathrm{~Pb}$ conditions when connected with the plastic tubing). The higher galvanic current compared to the prior situation where the lead pipe was connected to copper with a plastic connector and $0.3 \mathrm{~cm}$ distance is likely due to (1) changing the separation distance between lead and copper, (2) adding a third metal such as brass, and (3) creating crevices as described by Clark et al. (2013). Across all conditions, the sacrificial galvanic current of the lead pipe (through connection to brass or copper) strongly correlated to lead release (Fig. 9).

Contrary to expectations, the "worst case condition" of lead release and galvanic corrosion occurred when two lead pipes were connected through a brass connector (Fig. 7). While the magnitude of this effect was initially surprising, in retrospect it is explained by the fact that this condition creates two lead:copper alloy junctions and crevices. Lead release increased sharply (14-19 times higher) for the two
$100 \% \mathrm{~Pb}$ conditions with brass or copper connectors immediately after connection (Fig. 10). Lead in water for the copper sleeve connection returned to levels slightly above the plastic connector at the end of the sampling period while lead release from the brass compression connector remained elevated (Fig. 10). This finding further supports that prior research results in experiments using lead pipe connected to the copper pipe are conservative in terms of galvanic impacts on lead release relative to "real world" connectors (Edwards, 2012). Clearly, well-passivated lead pipes connected to the copper pipe through commercial brass connectors can sometimes create severe lead contamination from galvanic corrosion, consistent with results of other recent work using a harvested lead pipe that had been exposed for decades in distribution systems or field studies (Cartier et al., 2013; Wang et al., 2012, 2013; Del Toral et al., 2013; Welter et al., 2013).

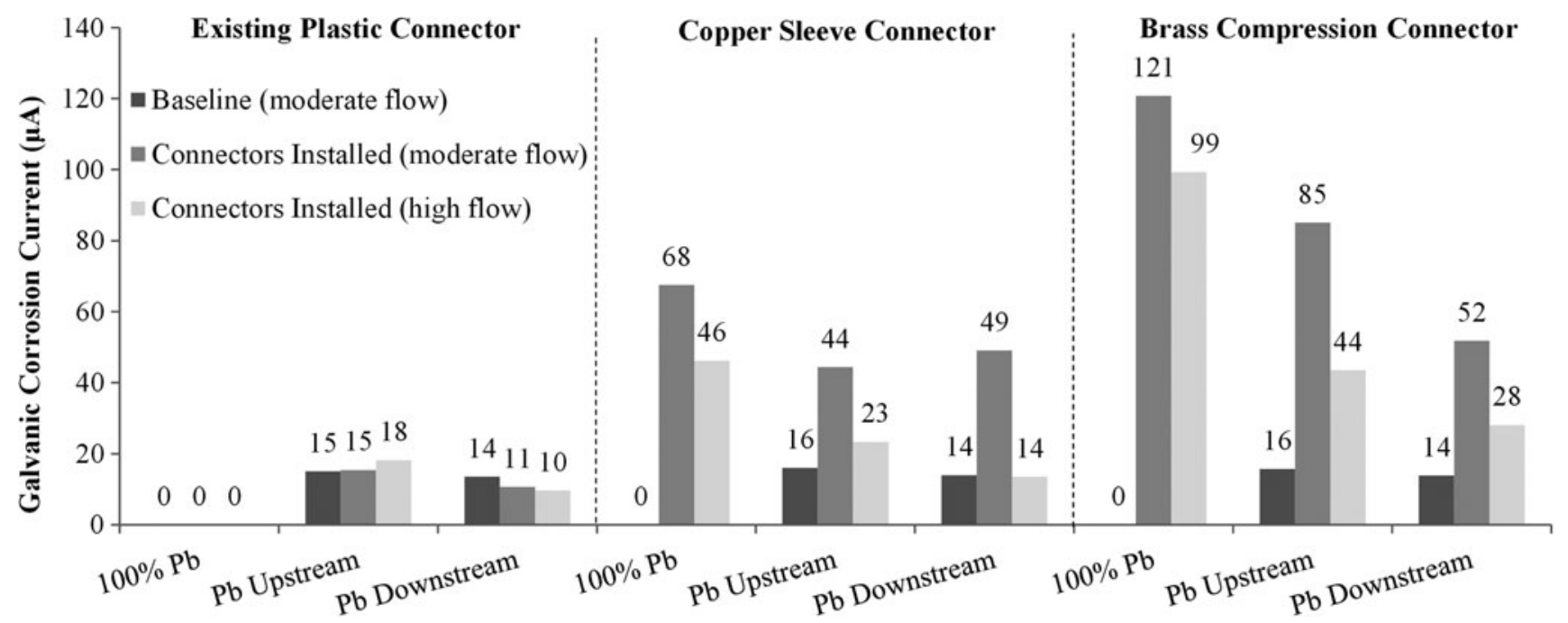

FIG. 8. Galvanic corrosion currents before and after installing connectors and Phase E. 


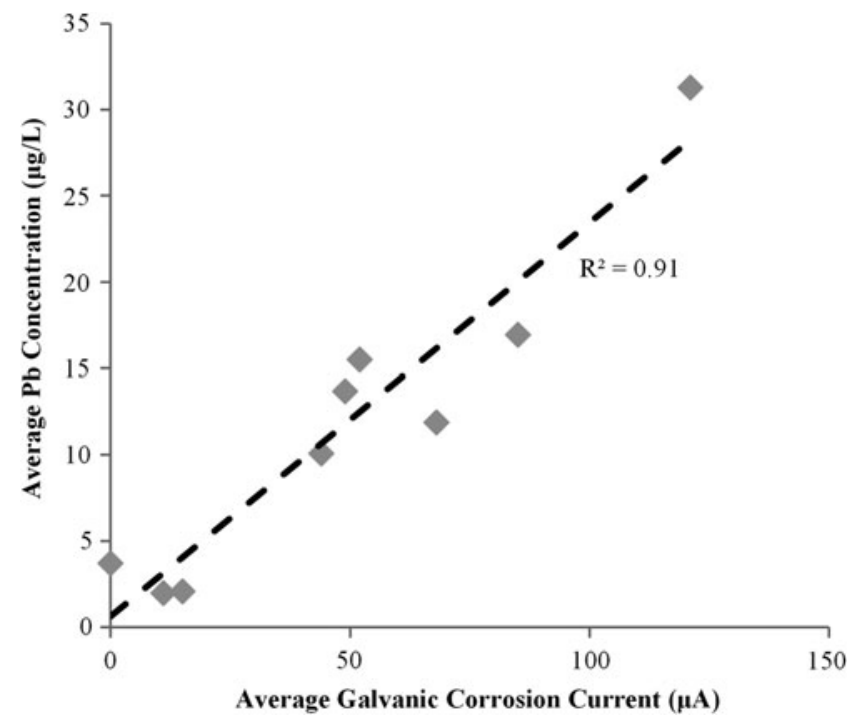

FIG. 9. Average $\mathrm{Pb}$ in water versus average galvanic current with connectors installed.

\section{Phase D: prolonged stagnation event}

During a 1-month stagnation event, the mass of lead released to water from either a $100 \%$ lead pipe or simulated direct $\mathrm{Pb}: \mathrm{Cu}$ pipe connections was $3000-4000 \mathrm{ppb}$ in a $2 \mathrm{~L}$ sample (Supplementary Fig. S3). The use of copper sleeves and brass connectors had between three and seven times higher lead release. Over the month, long stagnation event galvanic corrosion currents dropped only $42-82 \%$ compared to that measured after an $8 \mathrm{~h}$ stagnation time. Clearly, prolonged stagnation raises health concerns in systems with partial replacements.

\section{Phase E: detecting problems with particulate lead using filters and synthesis of sampling methods}

Filters were installed downstream of the various conditions and allowed to collect lead for two periods of 38 days while operating the rig at a relatively high flow rate (18-20 LPM) for a short duration of time (separated by long periods of stagnation). Additional $2 \mathrm{~L}$ first flush samples were collected without the filters at the end of both time periods. For both
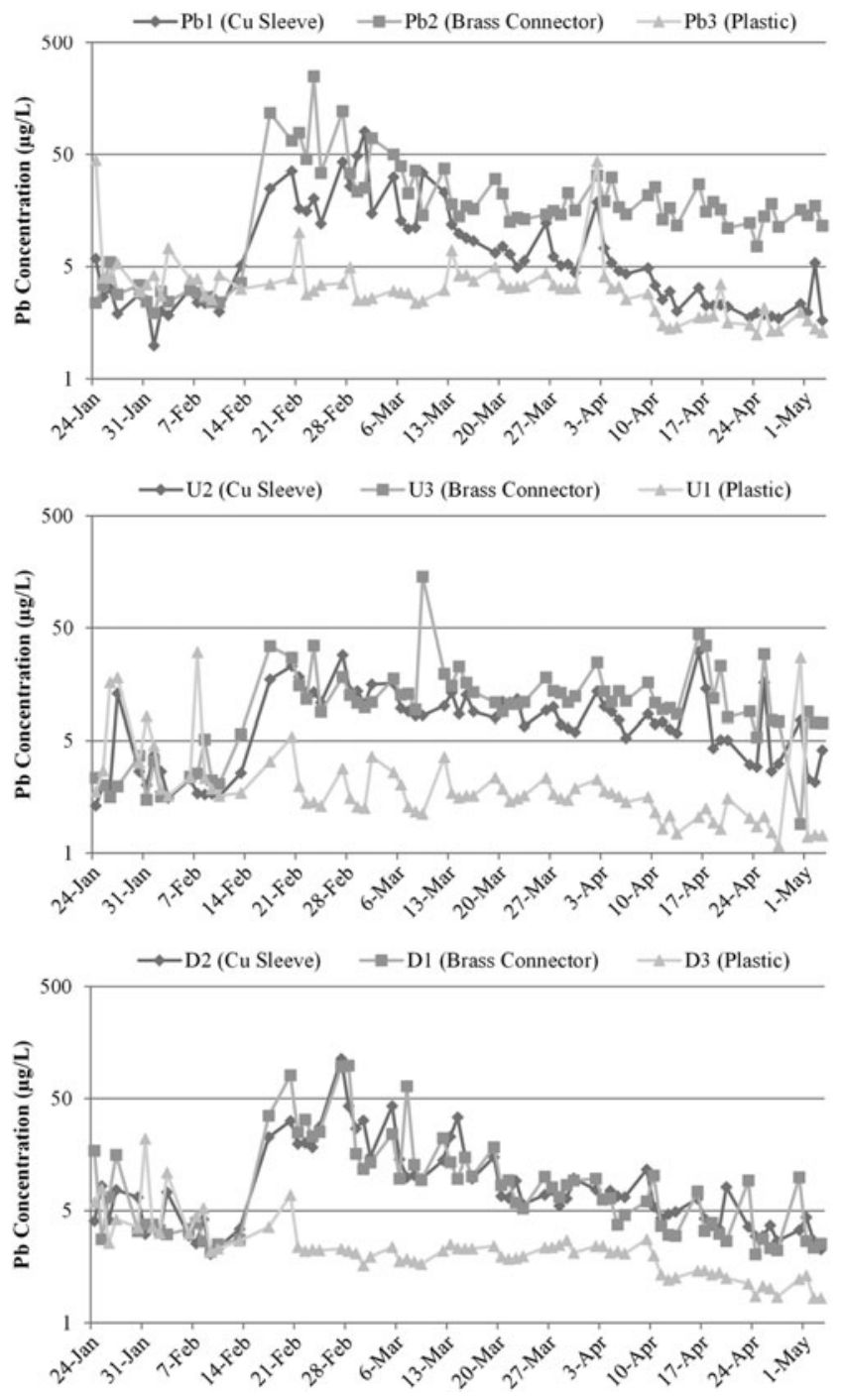

FIG. 10. Lead in water for $100 \% \mathrm{~Pb}$ conditions with connectors installed for duration of Phase $\mathrm{C}(N=70$ for each condition). 


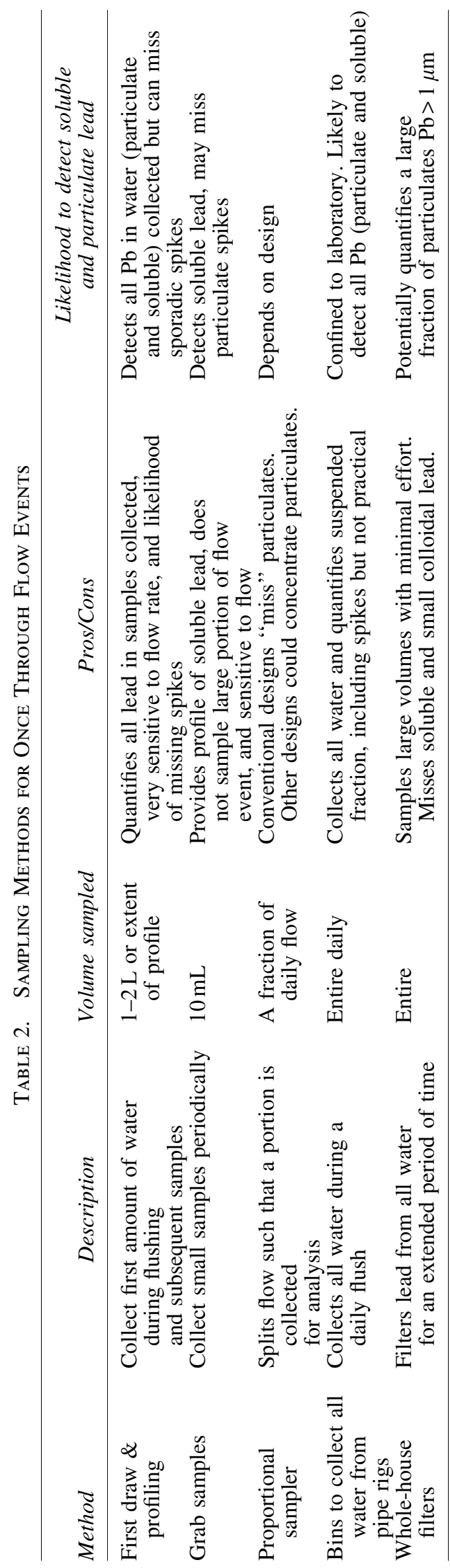

sampling methods, $\mathrm{Pb}$ in water increased with increasing galvanic corrosion current (Supplementary Fig. S4). Pb recovered using the filters was better correlated with galvanic current than the first $2 \mathrm{~L}$ samples $\left(R^{2}=0.41\right.$ and $R^{2}=0.23$, respectively). One time sampling events, such as the first $2 \mathrm{~L}$ samples, are useful but imperfect since high variability is expected from semirandom release of particulates during the high flow events. However, the representative sampling from the service line correlated strongly $\left(R^{2}=0.85\right)$ with the cumulative $\mathrm{Pb}$ captured by filters over the 1-month experiment with only one exception $\left(R^{2}=0.72\right.$, including exceptional point).

Filters were installed downstream of the various conditions and allowed to collect lead for 37 days while operating the rig at a relatively high flow rate (18-20 LPM) for short periods of time (separated by long periods of stagnation). The daily mass collected on the filters correlated strongly with prior data in which all the flow was collected in bins the prior 5 weeks and at a lower flow rate. In summary, whole-house filters have promise in detecting problems arising from particulate lead release from service lines in real systems. Galvanic currents decreased slightly $(\sim 20 \%)$ during this phase of testing, presumably due to passivation of the lead pipe from the initial increased galvanic corrosion rates (Supplementary Fig. S4).

During months 35-48, rigs were continuously sampled using the filters as described previously, and there was no difference between configurations that were partially replaced compared to that of the $100 \%$ lead pipe section. Thus, in this water, 4 years of exposure and removal of lead reservoirs were required, before a lead release from a partially replaced lead pipe was not worse than a full-lead pipe. The Blacksburg water did contain chloramine, which has been reported to cause more persistent and serious elevations of lead with galvanic connections than free chlorine (Arnold and Edwards, 2012; Zhou et al., 2015).

The array of sampling methods used in this work to detect health risks to consumers arising from sporadic particulate lead release from service lines each had potential benefits and drawbacks (Table 2). Profiling at high or low flow is a useful tool to quantify lead release, but large numbers of samples must be collected at a range of flow rates to quantify the nature of particulate lead release, and it is always possible that a propensity for very large spikes in water lead might be missed (Cartier et al., 2012a; Clark et al., 2012). Collecting a few grab samples (e.g., second draw) is even more prone to missing semirandom release of particulate lead. Proportional samplers can be used to collect fractions of total daily flow (van den Hoven and Slaats, 2006); however, our experiences demonstrate that these conventional designs may systematically "miss" larger lead particulates because the momentum of particles carries them past small side stream samplers and causes the lead to be "missed." Conversely, other designs may concentrate lead particulates in water samples.

The least ambiguous approach used in this research, through collection and sampling all the water passing through the service line over a period of weeks, is obviously not practical in consumer homes. However, if the whole-house filters captured a large fraction of the particulate lead (the dominant fraction of lead released), filters can detect problems from service lines in a single sample (the filter), improve the quality of consumed water in the home through removal of some lead particulates, eliminate the need for required 
stagnation events before collection, create a composite sample (for large captured particulates) at representative flow rates, and use patterns without interfering with the consumers' daily routine. These advantages of using filters in field work on partial lead service lines may outweigh the disadvantages of missing soluble lead.

\section{Phase F: exploring concerns related to unlined iron main connections to service line}

If there was no copper pipe installed between the iron main and lead pipe, the iron cathodically protected the lead pipe with an initial current of $92 \mu \mathrm{A}$. However, in all cases when the length of copper installed between the two pipes was $>2.5 \mathrm{~cm}$, the lead was sacrificed by the connection to copper. Thus, in a conventional partial replacement, where copper pipe lengths of $>2.5 \mathrm{~cm}$ are used, a connection of the service line to unlined iron is not expected to influence galvanic corrosion problems.

This was further confirmed by temporarily connecting a $3 \mathrm{~m}$ galvanized iron pipe section to the individual pipe rigs in this work. The iron pipe section did sacrificially reduce lead corrosion rates (measured by galvanic current, 12-15 $\mu \mathrm{A}$ ) in cases where the iron was directly connected to lead, as occurs in the field before partial replacement. However, for the case in which $1.5 \mathrm{~m}$ of copper was placed between the lead and iron as per a traditional partial replacement, the galvanic current between copper:lead was not affected by the upstream connection between copper:iron. In summary, this short-term experiment suggests that there could be some very small benefits to lead release if a lead pipe is connected to an unlined iron main, but sacrificial currents from the unlined iron main will not reduce galvanic impacts of copper on lead pipe corrosion in a traditional partial service line replacement. Clearly, there are also other detriments from lead mobilization by iron particulates through a sorption mechanism as illustrated elsewhere (Hulsmann, 1990; Lytle et al., 1993; Triantafyllidou et al., 2007; Deshommes et al., 2010; Cartier et al., 2012b; Schock et al., 2014; Masters et al., 2015).

\section{Conclusions}

- After 14 months of exposure, starting with new lead pipe and no scale and without any disturbances from cutting pipes, configurations representative of partial pipe replacements continued to release much more lead than the full-lead service pipe at moderate and high flow rates (as observed in Cartier et al., 2012a). Under low flow rate sampling, lead release is comparable between the three conditions tested. However, at moderate and high flow rates, galvanic corrosion increased lead in water for $\mathrm{Pb}-\mathrm{D}$ by a factor of 26 compared to $100 \% \mathrm{~Pb}$ at highest flow.

- When a consistent moderate flow rate was used, galvanic corrosion increased lead release from a partial service line configuration, and these effects were significant for a period of at least 48 months. By the end of this experiment, the particulate lead release from the partial pipe ( $\mathrm{Pb}-\mathrm{U}$ and $\mathrm{Pb}-\mathrm{D})$ was comparable to the full- $\mathrm{Pb}$ pipe, even though the surface of lead in contact with water is $50 \%$ lower.
- Galvanic current contributed to reservoirs of lead rust/ scale accumulation in the downstream plumbing that created spikes of particulate lead. Galvanic corrosion currents had decreased 35-50\% from initial rates after 2 years of operation, but still persisted at rates greater than $10 \mu \mathrm{A}$.

- The addition of brass and copper connectors to the passivated lead pipe dramatically increased lead corrosion and subsequent lead in water, apparently by the formation of crevices and galvanic corrosion. Lead leaching was markedly higher in conditions with brass compression fittings compared to plastic connectors with a dielectric spacer. Negative effects from galvanic corrosion and brass connectors, during exceptionally long stagnation events, created serious issues with elevated lead. Galvanic corrosion from newly installed brass connectors coupled to the lead pipe increased total lead mass release 5-7 times.

- Cathodic protection from iron mains coupled to lead does not appear to be capable of stopping problems arising from galvanic copper:lead connections.

- Collecting all water from the service pipes identified some important trends in total lead release that first draw and grab samples missed. While further research is required, whole-house filters can be utilized as an experimental collection method, capable of quantifying a fraction of the total particulate lead release while also partly mitigating lead in water risks for consumers.

\section{Acknowledgments}

The authors acknowledge the financial support of the Robert Wood Johnson Foundation (RWJF) under the Public Health Law Research Program. Opinions and findings expressed herein are those of the authors and do not necessarily reflect the views of the RWJF. The efforts of Dr. Michèle Prévost, who contributed to the design and conceptualization of this research, were greatly appreciated.

\section{Author Disclosure Statement}

No competing financial interests exist.

\section{References}

APHA. (1998). Standard Methods for the Examination of Water and Wastewater, APHA, AWWA, WEF.

Arnold, R.B., and Edwards, M. (2012). Potential reversal and the effects of flow pattern on galvanic corrosion of lead. Environ. Sci. Technol. 46, 10941.

Boyd, G.R., Reiber, S.H., McFadden, M., and Korshin, G. (2012). Effect of changing water quality on galvanic coupling. J. AWWA. 104, E136.

Breach, R.A., Crymble, S., and Porter, M.J. (1991). A Systematic Approach to Minimizing Lead Levels at Cosumers' Taps. Paper presented at the American Water Works Association Annual Conference and Exposition, Philadephia: PA. Britton, A., and Richards, W.N. (1981). Factors influencing plumbosolvency in Scotland. J. Inst. Water Eng. Sci. 35, 349. Brown, M.J., and Margolis, S. (2012). Lead in Drinking Water and Human Blood Lead Levels in the United States. Morbidity and mortality weekly report. Surveillance summaries. Washington: DC, p. 61, 1. 
Cartier, C., Arnold, R.B., Jr., Triantafyllidou, S., Prévost, M., and Edwards, M. (2012a). Effect of Flow Rate and Lead/ Copper Pipe Sequence on Lead Release from Service Lines. Water Res. 46, 4142.

Cartier, C., Doré, E., Laroche, L., Nour, S., Edwards, M., and Prévost, M. (2013). Impact of Treatment on Pb Release from Full and Partially Replaced Harvested Lead Service Lines (LSLs). Water Res. 47, 661.

Cartier, C., Nour, S., Richer, B., Deshommes, E., and Prévost, M. (2012b). Impact of water treatment on the contribution of faucets to dissolved and particulate lead release at the tap. Water Res. 46, 5205.

Clark, B., Cartier, C., St. Clair, J., Triantafyllidou, S., Prévost, M., and Edwards, M. (2013). Effects of commercial connectors on galvanic corrosion between $\mathrm{Pb} / \mathrm{Cu}$ pipes. $J$. Am. Water Works Assoc. Accepted; pp. E576-E586; http://dx.doi. org/10.5942/jawwa.2013.105.0113

Clark, B., Hernandex, A.L., and Edwards, M. (2011). Deposition Corrosion of Water Distribution System Materials. Paper presented at the Water Quality Technology Conference, Phoenix, AZ.

Clark, B., Masters, S., and Edwards, M. (2012). 3-D Lead Profiling Detects Particulate Lead-in-Water Risks as a Function of Flow Rate. Paper presented at the Water Quality Technology Conference, Toronto, ON.

Clark, B., St. Clair, J., and Edwards, M. (2015) Copper deposition corrosion elevates lead release to potable water. J. Am. Water Works Assoc. 107, E627-E637.

Copper Development Association. (1999). Copper Tube in Domestic Water Services Publication 33. Available at: http://www.copper .co.za/downloads/library/33-Copper-Tube-in-Domestic-WaterServices.pdf (accessed November 25, 2015).

Del Toral, M.A., Porter, A. and Schock, M.R. (2013). Detection and evaluation of elevated lead release from service lines: a field study. Environ. Sci. Technol. 47, 9300.

Deshommes, E., Laroche, L., Nour, S., Cartier, C., and Prévost, M. (2010). Source and occurrence of particulate lead in tap water. Water Res. 44, 3734.

Doré, E., Cartier, C., Edwards, M., DeSantis, M., Schock, M., Laroche, L., Nour, S., and Prévost, M. (2012). Impact of Treatment on Scale Formation and Lead Release from aged LSLs. Paper presented at the American Water Works Association, WQTC, Toronto, CA.

Edwards, M. 2012. Discussion: Effect of Changing Water Quality on Galvanic Coupling. J. Am. Water Works Assoc. 104, 65.

Edwards, M. 2014. Fetal death and reduced birth rates associated with exposure to lead-contaminated drinking water. Env. Sci. Tech. 48, 739.

Gehring, Jr., G., Lindemuth, D., and Young, W. (2003). Break Reduction/Life Extension Program for Cast and Ductile Iron Water Mains. New Pipeline Technologies, Security, and Safety: pp. 321-331. doi: 10.1061/40690(2003)30

Giammar, D.E., Welter, G.J., and Cantor, A. (2012). Review of previous water research foundation projects on galvanic corrosion. Water Res. Found. Retrieved from www.waterrf.org/ ProjectsReports/ProjectPapers/Lists/PublicProjectPapers/ Attachments/3/4349_LiteratureReview.pdf.

Giani, R. (2008). Possible Influence of Galvanized Plumbing in Elevated Lead Levels. Paper presented at the American Water Works Association Annual Conference and Exposition, Atlanta, GA.

Giani, R., Edwards, M., Chung, C., and Wujek, J. (2004). Use of Lead Profiles to Determine Source of Action Level Exceedances from Residential Homes in Washington. Paper pre- sented at the DC Proceedings AWWA Water Quality Technology Conference Sunday Workshop. San Antonio, TX. Hulsmann, A.D. (1990). Particulate lead in water supplies. Water Environ. J. 4, 19.

HDR Engineering, Inc. (2009). An Analysis of the Correlation Between Lead Released from Galvanized Iron Piping and the Contents of Lead in Drinking Water. Bellevue, WA: HDR Engineering, Inc.

Hu, J., Gan, F., Triantafyllidou, S., Nguyen, C.K., and Edwards, M. (2012). Copper-induced metal release from lead pipe into drinking water. Corrosion. 68, 1037.

Lytle, D.A., Schock, M.R., Dues, N.R., and Clark, P.J. (1993). Investigating the preferential dissolution of lead from solder particulates. J. Am. Water Resources Assoc. 85, 104.

McNeill, L.S., and Edwards, M. (2004). Importance of Pb and $\mathrm{Cu}$ particulate species for corrosion control. J. Environ. Eng. 130, 136.

Masters, S., Parks, J., Atassi, A., and Edwards, M.A. (2015). Distribution system water age can create premise plumbing corrosion hotspots. Environ. Monit. Assess. 187, 1.

Muylwyk, Q., Waller, M., Spielmacher, A., Olesiuk, J., and Suffoletta, V. (2011). Full versus partial lead service line replacement and lead release in a well buffered groundwater. Paper presented at the American Water Works Association, Water Quality Technology Conference, Phoenix, AZ.

NDWAC (National Drinking Water Advisory Council) (2011). Letter to EPA Administrator on Revised Lead and Copper Rule. Retrieved November 25, 2015, from http://water.epa.gov/drink/ ndwac/upload/ndwaclettertoepadec2011.pdf

Rajani, B., and Kleiner, Y. (2003). Protecting ductile-iron water mains: what protection method works best for what soil condition? J. Am. Water Works Assoc. 95, 110.

Reiber, S., and Dufresne, L. (2006). Effects of External Currents and Dissimilar metal contact on Corrosion of Lead from Lead Service Lines. Philadelphia: Final Report to USEPA region III.

Retraction Watch. (2015). Expression of concern opens floodgates of controversy over lead in water supply. Available at: http:// retractionwatch.com/2015/04/15/expression-of-concern-opensfloodgates-of-controversy-over-lead-in-water-supply/ (accessed June 29, 2015).

Schock, M.R., Cantor, A.F., Triantafyllidou, S., Desantis, M.K., and Scheckel, K.G. (2014). Importance of pipe deposits to Lead and Copper Rule compliance. J. AWWA. 106, 7.

St. Clair, J., Stamopoulos, C., and Edwards, M. (2012). Technical note: increased distance between galvanic lead:copper pipe connections decreases lead release. Corrosion. 68, 779.

Swertfeger, J., Harman, D.J., Shrive, C., Metz, D.H., and DeMarco, J. (2008). Water quality effects of partial lead line replacement. Paper presented at the American Water Works Association Annual Conference and Exposition, San Antonio, TX.

Swertfeger, J., Metz, D.H., and Webb, D. (2011). Benefits of a utility lead research program. Paper presented at the American Water Works Association Annual Conference and Exposition, Washington, DC.

Triantafyllidou, S., and Edwards, M. (2010). Contribution of galvanic corrosion to lead in water after partial lead service line replacements. Water Res. Found. Report No. 4088.

Triantafyllidou, S., and Edwards, M. (2011). Galvanic corrosion after simulated small-scale partial lead service line replacements. J. Am. Water Works Assoc. 103, 85.

Triantafyllidou, S., Gallagher, D., and Edwards, M. (2014). Assessing risk with increasingly stringent public health goals: 
the case of water lead and blood lead in children. J. Water Health. 12, 57.

Triantafyllidou, S., Parks, J., and Edwards, M. (2007). Lead particles in potable water. J. Am. Water Works Assoc. 99, 107.

US EPA. (1991). Maximum Contaminant Level Goals and National Primary Drinking Water Regulations for Lead and Copper. (Federal Register 56, 26460).

US EPA. (2011). Science Advisory Board Evaluation of the Effectiveness of Partial Lead Service Line Replacements, EPA-

SAB-11-015 Retrieved 2012/02/15, from http://yosemite.epa .gov/sab/SABPRODUCT.nsf/RSSRecentHappeningsBOARD/ 964CCDB94F4E6216852579190072606F/\$File/EPA-SAB11-015-unsigned.pdf

US EPA. (2012). Long-Term Revision for the Lead and Copper Rule (LCR), Retrieved 2013/06/11, from www.epa.gov/rfa/ lead-copper.html

van den Hoven, T., and Slaats, N. (2005). Lead Monitoring, in Analytical Methods for Drinking Water: Advances in Sampling and Analysis (eds P. Quevauviller and K. C. Thompson),
John Wiley \& Sons, Ltd, Chichester, UK. doi: 10.1002/ 0470094931.ch3

Wang, Y., Jing, H., Mehta, V., Welter, G.J., and Giammar, D.E. (2013). Effect of connection methods on lead release from galvanic corrosion. J. Am. Water Works Assoc. 105, 337.

Wang, Y., Jing, H., Mehta, V., Welter, G.J., and Giammar, D.E. (2012). Impact of galvanic corrosion on lead release from aged lead service lines. Water Res. 46, 5049.

Welter, G., Giammar, D., Wang, Y., and Cantor, A. (2013). Galvanic corrosion following partial lead service line replacement. Water Res. Found. Report No. 4349.

Xie, Y., and Giammar, D.E. (2011). Effects of flow and water chemistry on lead release rates from pipe scales. Water Res. 45, 6525 .

Zhou, E., Payne, S.J.O., Hofmann, R., and Andrews, R.C. (2015). Factors affecting lead release in sodium silicatetreated partial lead service line replacements. J. Environ. Sci. Health A Tox. Hazard. Susbst. Environ. Eng. 50, 922. 